\title{
Políticas de responsabilidad social y sus formas de difusión de diez corporativos multinacionales líderes que operan en México
}

María Antonieta Rebeil Corella

- Directora del Centro de Investigación para la Comunicación Aplicada (CICA) de la Universidad Anáhuac México Norte

- Co-Coordinadora con Jacinta Hernández Pérez del Grupo de Investigación de la Comunicación Integral en las Organizaciones, de la Asociación Mexicana de Investigadores de la Comunicación

- arebeil@anahuac.mx

Clemente Sánchez Uribe

- Investigador del CICA

- Director de Promoción y Mercadotecnia de la Asociación Mexicana de Comunicadores (AMCO)

- clemente.sanchez@anahuac.mx

Con la colaboración de:

\section{Guillermo Lemus Legaspi}

- Pasante de la Licenciatura en Comunicación de la Universidad Anáhuac México Norte

- Asistente de investigación del CICA

- memin_leg@hotmail.com

Mariana Moreno Moreno

- Pasante de la Licenciatura en Comunicación de la Universidad Anáhuac México Norte

- Asistente de investigación del CICA

- mariana.moreno1@yahoo.com 
Resumo

Apresentam-se os resultados da pesquisa sobre as práticas de responsabilidade social (RS) adotadas no México por dez corporações multinacionais. Discute-se o conceito de RS, sua relação com a ética, e se analisa uma amostra de notas de imprensa online para comparar o que as empresas sustentam com o que realizam. Oferecem-se idéias acerca das implicações que isso tem para a comunicação e se questiona de que forma uma corporação deve gerir seus processos de comunicação. Conclui-se que a RS penetrou na consciência e nas atividades das corporações estudadas. Entretanto, ao passo que algumas já a integraram ao seu dia-a-dia, outras ainda a encaram como parte separada de seu trabalho.

PALAVRAS-CHAVE: RESPONSABILIDADE SOCIAL • COMUNICAÇÃO ORGANIZACIONAL • ÉTICA EM-

PRESARIAL • CORPORAÇÕES MULTINACIONAIS • NOTAS DE IMPRENSA

\begin{abstract}
Presents the results of the survey concerning the social responsibility (SR) practices adopted in Mexico by ten multinational corporations. There is discussion of the concept of SR, of its relation with ethics, as well as analysis of a sample of online press releases to compare what the companies sustain and what they achieve. Ideas are offered concerning the implications that this causes for communication and it is questioned how a corporation should manage its communication processes. It is concluded that SR penetrated into the conscience and into the activities of the corporations surveyed. However, while some of them have already integrated it with their daily routines, others still see it as a segregated part of their work.
\end{abstract}

KEYWORDS: SOCIAL RESPONSIBILITY • ORGANIZATIONAL COMMUNICATION • BUSINESS ETHICS

- MULTINATIONAL CORPORATIONS • PRESS RELEASES

\title{
Resumen
}

Se presentan los resultados de la investigación sobre las prácticas de responsabilidad social (RS) adoptadas en México por diez corporaciones multinacionales. Se discute el concepto de RS, su relación con la ética, y se analiza una muestra de notas de prensa online para contrastar lo que las empresas sustentan y lo que realizan. Se ofrecen ideas acerca de las implicaciones que ello tiene para la comunicación y se cuestiona de qué modo una corporación debe gestionar sus procesos de comunicación. Se concluye que la RS ha penetrado en la consciencia y en las actividades de las corporaciones estudiadas. Sin embargo, mientras algunas ya la han integrado a su proceder diario, otras aún la llevan a cabo como parte separada de su trabajo.

PALABRAS CLAVE: RESPONSABILIDAD SOCIAL • COMUNICACIÓN ORGANIZACIONAL • ÉTICA EMPRESARIAL • CORPORACIONES MULTINACIONALES • NOTAS DE PRENSA 


\section{Ética empresarial}

Dara iniciar, es necesario hacer una breve reflexión acerca de la ética empresarial y su importancia. La ética se refiere a la conducta justa y equitativa, que va mucho más allá del cumplimiento de las leyes. Implica adherirse a principios morales, guiarse por los valores universales, y ajustarse al comportamiento de vida. La ética tiene como centralidad a la persona humana y su dignidad infinita. Es fundamental considerar que las personas son fines y nunca medios. El respeto y la promoción de su desarrollo integral a las personas son el criterio fundamental para conocer si una acción es ética o no.

Algunas políticas dentro de las corporaciones que se consideran en el marco de este planteamiento inicial tienen que ver con: a) salarios que reflejan la productividad del trabajador y las necesidades de su familia; b) el subsidio a gastos de la educación del trabajador; c) horarios y estilos de trabajo; d) la capacitación; e) apoyo para que las familias de los trabajadores tengan acceso a actividades deportivas y culturales; f) políticas justas en la contratación de la mujer y el derecho a la maternidad; entre otros.

Estas políticas, de acuerdo con la Education Fund, Business for Social Responsibility, han permitido ubicar beneficios concretos en la corporación tras implementar programas de ética empresarial (Cuadro 1).

Cuadro 1. Beneficios de implementar programas de ética en los procesos de la responsabilidad social empresarial

\begin{tabular}{l|l}
\hline Beneficio & Argumentación \\
\hline $\begin{array}{l}\text { Mejora del desempeño } \\
\text { financiero }\end{array}$ & $\begin{array}{l}\text { Un estudio realizado por la Universidad DePaul en 1999, entre 300 grandes } \\
\text { compañ́as, encontró que las firmas que hacían un compromiso explícito } \\
\text { de ceñirse al código de ética lograban ser valoradas por sus accionistas } \\
\text { más del doble que las que no lo hacían. }\end{array}$ \\
\hline $\begin{array}{l}\text { Favorece las ventas, } \\
\text { imagen y reputación }\end{array}$ & $\begin{array}{l}\text { A partir de una encuesta realizada en 1999 a consumidores de 23 países, } \\
\text { se encontró que en 15 de los países encuestados, la tercera parte de los } \\
\text { consumidores creen que un rol importante de las grandes empresas en la } \\
\text { sociedad actual es establecer altos estándares éticos y contribuir en la } \\
\text { construcción de una sociedad mejor. (Encuesta dirigida por Envitronics } \\
\text { International en conjunto con The Prince of Wales Business Leaders } \\
\text { Forum y The Conference Board). }\end{array}$ \\
\hline $\begin{array}{l}\text { Fortalece la lealtad } \\
\text { y compromiso } \\
\text { de los trabajadores }\end{array}$ & $\begin{array}{l}\text { Una encuesta realizada a trabajadores de los EEUU en 1999 por la } \\
\text { Walker Information y Hudson Institute encontró que sólo 9\% de los } \\
\text { trabajadores piensan que sus jefes no se comportan éticamente, } \\
\text { se encuentran inclinados a permanecer en sus empresas, mientras que } \\
55 \% \text { de quienes creen que sus líderes se comportan éticamente desean } \\
\text { continuar trabajando. }\end{array}$ \\
\hline
\end{tabular}

116 POLITICAS DE RESPONSABILIDAD SOCIAL Y SUS FORMAS DE DIFUSIÓN DE DIEZ CORPORATIVOS MULTINACIONALES LÍDERES QUE OPERAN EN MÉXICO - mARía ANTONIETA REBEIL CORELLA • CLEMENTE SÁNCHEZ URIBE • GUILLERMO LEMUS LEGASPI • MARIANA MORENO MORENO 


\begin{tabular}{l|l}
$\begin{array}{l}\text { Evita multas, } \\
\text { reparaciones impuestas } \\
\text { por la corte y cargos } \\
\text { criminales }\end{array}$ & $\begin{array}{l}\text { La Comisión Europea, que tiene el poder para imponer multas de } 10 \% \\
\text { de los ingresos de una compañía, multó a Volkswagen con más de } 90 \\
\text { millones de dólares en 1998, por violar las leyes de la libre competencia. } \\
\text { En 1999, Bankers Trust Co., fue multada con } 60 \text { millones de dólares } \\
\text { canadienses, porque tres de sus trabajadores realizaron falsos ingresos } \\
\text { para incrementar las utilidades del banco. }\end{array}$ \\
\hline $\begin{array}{l}\text { Evita pérdida en los } \\
\text { negocios }\end{array}$ & $\begin{array}{l}\text { En 1998, la Royal Dutch/Shell canceló } 69 \text { contratos con compañías } \\
\text { que habían fallado en su adhesión a sus políticas éticas de salud, } \\
\text { seguridad y ambientales. Los gobiernos también pueden cancelar } \\
\text { contratos o penalizar a las empresas que son percibidas poco éticas. }\end{array}$ \\
\hline Goza de mayor acceso & $\begin{array}{l}\text { El Social Investment Forum informó que en 1999 más de dos trillones } \\
\text { de dólares en activos fueron manejados por empresas que mostraban } \\
\text { prácticas éticas con el medio y la sociedad. Esto representa más de } \\
12 \% \text { de los } 16.3 \text { trillones en fondos administrados profesionalmente } \\
\text { en EUA. Empresas éticamente responsables acceden más rápida } \\
\text { y fluidamente a los capitales, que las que no presentan } \\
\text { este comportamiento. }\end{array}$ \\
\hline
\end{tabular}

Fuente: Education Fund (2003), La empresa éticamente responsable: buena, bonita y barata.

Los puntos anteriormente señalados tienen como trasfondo la consideración de que el hombre dentro de una empresa, sea cual sea la naturaleza de ésta, no es nunca un medio de producción, sino un fin en sí mismo.

\section{Algunos aspectos de la ética laboral en México}

En el México actual, el derecho al trabajo y las implicaciones de ello son frecuentemente violadas. Todo hombre tiene derecho a la vida, al desarrollo personal, al respeto, la autovalía, al empleo y a hacer contribuciones a la sociedad. ¿Cómo decir si el empleo en México contiene los principios de la ética empresarial?

Para ello, en primer lugar se deben discutir los niveles de desempleo que existen en el país y los problemas de migración a los Estados Unidos de Norteamérica. De una población económicamente activa (PEA) de 42 millones, existe un desempleo de un millón 786 mil desempleados, o sea el 4.06\% de la PEA (GONZÁLEZ, 2008). Considerando que, el empleo formal de la PEA es de aproximadamente 18 millones: 15 millones en el sector privado y 3 millones en el sector público. Los restantes 24 millones (aproximadamente) pertenecen al sector informal o bien, están desempleados (INEGI, 2008).

Por otra parte, el número de connacionales ilegales que habitan en el territorio norteamericano es de más de diez millones. La cantidad de personas que cruzan la frontera, en busca de trabajo es de alrededor de 2 mil personas, diariamente.

Estas cifras pueden ser un termómetro acerca de si el derecho al empleo es un factor que se esté fomentando en el país. 
Por otra parte, es importante señalar, que dentro de las corporaciones actuales en el país, en muchas de éstas, existen situaciones de cargas de más de ocho horas diarias en el trabajo, de empleo de niños, carencias en la capacitación del personal, discriminación de la mujer y en general, de gente con capacidades diferentes, entre otros. Hay una gran cantidad de empleos que reducen a los trabajadores en calidad de máquinas negándoles el derecho que tienen a desarrollarse física, emocional y espiritualmente mediante la realización de su trabajo. Por otra parte, la injusticia salarial en muchos casos se hace presente como un fenómeno de nuestra sociedad.

En términos generales, la existencia de los principios éticos en las corporaciones actuales del país, es u na meta pendiente y que requiere de muchos esfuerzos para ser lograda. Entre otras cuestiones, hacen falta más estudios a profundidad y propuestas correspondientes para conformar un marco de referencia adecuado para las corporaciones empleadoras en el país.

\section{La responsabilidad social como parte de la ética en las corporaciones}

Una de las vías para practicar la ética organizacional es la responsabilidad social empresarial. Se puede hablar de las finalidades de las corporaciones en términos de si éstas son de tipo individual o social (Cuadro 2).

\section{Cuadro 2. Objetivos y finalidades de las organizaciones}

\begin{tabular}{l|l|l}
\hline & Objetivo económico & Objetivo personal \\
\hline Individual o interno & $\begin{array}{l}\text { Generar y distribuir equitativamente } \\
\text { el máximo valor agregado }\end{array}$ & $\begin{array}{l}\text { Contribuir al desarrollo integral } \\
\text { de todos los componentes }\end{array}$ \\
\hline Social o externo & $\begin{array}{l}\text { Producir bienes y servicios que } \\
\text { satisfagan las necesidades }\end{array}$ & $\begin{array}{l}\text { Contribuir al desarrollo integral } \\
\text { de la comunidad }\end{array}$ \\
\hline
\end{tabular}

Fuente: Hidalgo (2008). Centro de Investigación para la Comunicación Aplicada.

El contenido del Cuadro 2 señala cómo las corporaciones tienen objetivos económicos con una dimensión interna (generar y distribuir equitativamente las ganancias), con dimensiones también sociales (producir bienes y servicios que satisfagan las necesidades). De la misma manera se puede ver cómo se tienen objetivos personales con una dimensión interna (contribuir al desarrollo integral de todos los participantes) y con un nivel social o externo (contribuir al desarrollo integral de la sociedad). Lo importante es que se logre una combinación óptima de las cuatro esferas sin menospreciar ninguna de éstas.

La empresa socialmente responsable es necesariamente una empresa que deriva sus principios y sus funciones desde la ética. Ello le implica un compromiso con 
los principios y valores rectores pensados desde las intencionalidades y del comportamiento ético. Le implica también la generación de la riqueza, en el marco del respeto infinito de las personas que la integran, así como de los públicos que tienen que ver con ella. La empresa socialmente responsable se compromete a proporcionar bienes y servicios de calidad a la sociedad. La generación del mayor número de empleos posible, es otra característica de una empresa que se dice responsable socialmente.

\section{¿Qué es la responsabilidad social?}

Pero la pregunta subyace: ¿Qué es la responsabilidad social? Es muy importante reconocer que en el mundo de la teoría existen dos enfoques diferentes acerca de la Responsabilidad Social Empresarial: la liberal (FRIEDMAN, 1990) y la social (BELL, 1965). El primero supone que la corporación es un ámbito de atribución exclusivamente de los accionistas (shareholders), y por ende, asume responsabilidades únicamente frente a las ganancias económicas de éstos. El enfoque social, asume que una corporación supone un concepto mucho más amplio en donde involucra a públicos internos, externos y especiales. En este sentido, los accionistas son solamente un componente del conjunto de stakeholders y por ende, la corporación asume una responsabilidad social más amplia, dirigida al bienestar de todos los involucrados en la corporación y a la sociedad en la cual desarrolla sus actividades.

Juan Cajiga, de Cemefi, cita como definición de Responsabilidad Social Empresarial "el compromiso consciente y congruente de cumplir integralmente con la finalidad de la empresa tanto en lo interno, como en lo externo, considerando las expectativas de todos sus participantes en lo económico, social o humano y ambiental, demostrando el respeto por los valores éticos, la gente, las comunidades y el medio ambiente, y para la construcción del bien común." (2006)

Los aspectos que abarca la responsabilidad social organizacional tienen que ver en primer lugar con la decisión que tomó un entrepreneur o un conjunto de individuos que se cohesionan para llevar a cabo la producción eficiente de un bien o servicio y realizarlo en el mercado.

Estas actividades de tipo laboral y empresarial están sujetas a las leyes y normas que rigen una sociedad específica y en un momento histórico dado. Ello las hace unidades que son determinadas desde la sociedad más amplia que es su entorno. Ello mismo las hace tener la necesidad de responder a las demandas de este entorno.

Una empresa que pretende ser socialmente responsable hacia la sociedad en que se encuentra, tiene por obligación hacer otro tanto hacia el interior de su corporación. Los problemas del bienestar personal de cada uno de sus integrantes, su desarrollo fisico, intelectual, emocional y espiritual son partes integrantes de una estrategia comprehensiva de responsabilidad social. No es posible predicar lo que no se es. 
La responsabilidad social al interior de las unidades de negocio se remite a la integridad moral de los dirigentes y de todos los participantes, a la justicia en las transacciones, al buen trato del personal, el respeto a las leyes, la honestidad en la gestión, el trabajo solidario en equipo, y el sentido de logro y cooperación. El Dr. Imanol Belausteguigoitia refiere al respecto que en México, no es de extrañar que la gente da un valor trascendente a la sensibilidad emocional en las relaciones interpersonales. Por ello, dice que si se percibe en las corporaciones una tendencia a minimizar la importancia de la persona, se habla de una clara deshumanización del trabajo. Cita, adicionalmente:

"Se puede esperar que los trabajadores mexicanos se desempeñen mejor si primero se toma en cuenta a la persona y después la tarea. Se ha comprobado que un adecuado clima organizacional y un trato digno y socialmente responsable genera en las personas un mayor compromiso hacia sus organizaciones."

Por otra parte, la cuestión de la ecología que es la tradicionalmente asociada al concepto de responsabilidad social, no puede quedar relegada, ya que ésta implica el cuidado de los recursos naturales no renovables para las generaciones presentes y para las futuras.

En síntesis, entre los públicos más importantes que implican las acciones de la responsabilidad entendidos en este contexto como inversiones y no como gastos, están los actores más importantes en la empresa: clientes, empleados, sociedad y socios. Existen varias acciones posibles que se pueden convertir el inversiones que se hacen para ser socialmente responsable. Al respecto, en el caso de los clientes es necesario hacer inversiones en nivel de servicios, calidad, términos flexibles, involucramiento con el cliente, derechos e intereses de los consumidores y servicios del producto y desde luego ética en las relaciones con los clientes.

Con relación a los empleados, hay que hacer inversiones en: prestaciones para los empleados, salarios justos y provechosos, reclutamiento, entrenamiento y desarrollo, seguridad del ambiente de trabajo, involucramiento de los empleados, ética de las relaciones internas en la corporación.

En cuanto a la sociedad, las inversiones son en términos de manejo de desperdicios, buen vecino, reducción del riesgo medio ambiental, conservación de la energía, infraestructura, rehabilitación medio ambiental y la ética que se denota en la honestidad y la solidaridad hacia la comunidad en que se encuentra la empresa y la sociedad más amplia.

En cuanto a los socios de la corporación, éstos deben hacer inversiones en el manejo de sus marcas, la negociación de términos favorables, involucramiento de los socios, prácticas de comercio justas, transparencia mutua. Todo lo anterior debe estar basado en una relación ética de los accionistas con la empresa y la sociedad.

1 BELAUSTEGUIGOITIA, I. Empresas familiares y responsabilidad social en México. Recuperado en agosto/2008. Disponible en: http://cedef.itam.mx/PDF/empresasfamiliaresyresponsabilidad\%20socialenmexico.pdf 
Las reflexiones aquí realizadas, pueden ofrecer un parámetro referencial comparativo que permita hacer un contraste entre las actividades posibles a realizar en una empresa para garantizar que ésta funcione y sea una empresa socialmente responsable y lo que sucede en la realidad de las grandes corporaciones mexicanas.

\section{Actividades de responsabilidad social que realizan diez corporaciones líderes en el contexto nacional}

Las actividades específicas reportadas por los diez grupos empresariales en el estudio se pueden dividir en dos conjuntos: a) aquellos que tienen que ver con bebidas y alimentos y b) aquellos que tienen que ver con la tecnología de la información y las telecomunicaciones (Cuadro 3). A continuación se analizan los siguientes casos: Wal-Mart, cadena comercializadora; McDonald's, restaurantes de comida rápida; Sabritas, agroindustrial de botanas; Femsa, bebidas de calidad; Bimbo, panificación; Nestlé, productos alimenticios y dedicados a la nutrición; Telmex, servicios y productos de telecomunicaciones; HP, fabrica y comercializa hardware y software y brinda asistencia informática; Sony, fabrica y comercializa productos de electrónica y produce en la industria audiovisual; Microsoft, desarrolla, fabrica, licencia y produce software para equipos electrónicos.

La información recabada en el Cuadro 3, resume las políticas de responsabilidad social de estos grupos empresariales. Algunas de éstas se enfocan hacia el interior de la propia corporación, llevando a cabo programas que inciden en sus relaciones con clientes, asociados y proveedores. Otros grupos y cadenas insertan sus actividades hacia la sociedad en que realizan sus operaciones, casi todas, por su naturaleza internacional, cuentan con actividades de responsabilidad social en varias partes del mundo. Los temas más recurrentes que expresan tener estas corporaciones son proyectos de salud, cultura, educación, desarrollo humano, deporte, el cuidado del medio ambiente. Notablemente Telmex, cuenta con un destacado proyecto de mayor importancia para México: la Fundación Centro Histórico que por años ha venido realizando el rescate del centro de la Ciudad de México (Cuadro 3).

Cuadro 3. Políticas de responsabilidad social realizada por diez corporaciones multinacionales que operan en México

\begin{tabular}{|c|c|c|}
\hline Grupos & Descripción & Políticas de responsabilidad social \\
\hline Wal-Mart & $\begin{array}{l}\text { Wal-Mart de México es una } \\
\text { de las cadenas comerciales } \\
\text { más importantes de nuestro } \\
\text { país. }\end{array}$ & $\begin{array}{l}\text { - Actuar conforme a sus principios } \\
\text { - Buscar el desarrollo y calidad de vida } \\
\text { de sus asociados } \\
\text { - Operar eficientemente para lograr costos bajos y } \\
\text { ofrecer precios bajos a clientes y socios } \\
\text { - Invertir en México para generar empleos y } \\
\text { crecimiento para sus proveedores } \\
\text { - Trabajar con sus proveedores para promover la } \\
\text { competitividad } \\
\text { - Privilegiar la innovación }\end{array}$ \\
\hline
\end{tabular}




\begin{tabular}{|c|c|c|}
\hline & & $\begin{array}{l}\text { - Promover el trabajo voluntario de sus asociados } \\
\text { - Apoyar la alimentación sustentable de las } \\
\text { comunidades menos favorecidas en México } \\
\text { - Operar de manera respetuosa con el medio ambiente }\end{array}$ \\
\hline McDonald's & $\begin{array}{l}\text { Cadena de restaurantes } \\
\text { especializada en comida } \\
\text { rápida. Es una de las } \\
\text { empresas más famosas en el } \\
\text { mundo entero. }\end{array}$ & $\begin{array}{l}\text { - Desarrollo profesional de sus empleados (cerca } \\
\text { del } 95 \% \text { de los Gerentes comenzaron como } \\
\text { Empleados de Mostrador) } \\
\text { - Capacitación y entrenamiento constante } \\
\text { - Responsabilidad, trabajo en equipo, servicio, } \\
\text { autodisciplina y responsabilidad social } \\
\text { - Horarios flexibles, remuneraciones superiores a la } \\
\text { ley, respeto y compañerismo } \\
\text { - Reconocimiento del Instituto GPTW. Cinco años } \\
\text { consecutivos dentro del Top Ten Nacional y } \\
\text { reconocimiento como una de las mejores } \\
\text { empresas para trabajar en Latinoamérica } \\
\text { - Cursos y salidas de integración } \\
\text { - Becas de estudio } \\
\text { - Oportunidades para gente con capacidades } \\
\text { diferentes para formar parte del staff de trabajo } \\
\text { - Apoyo a la comunidad a través de programas } \\
\text { de educación, deporte, salud, niñez, adultos } \\
\text { mayores, personas con capacidades diferentes, } \\
\text { concientización ciudadana }\end{array}$ \\
\hline Sabritas & $\begin{array}{l}\text { Es una empresa agroindustrial } \\
\text { líder en el mercado de } \\
\text { botanas y alimentos } \\
\text { divertidos. Es reconocida por } \\
\text { la calidad, variedad y sabor } \\
\text { de sus productos. }\end{array}$ & $\begin{array}{l}\text { Es una empresa que trabaja en diversos grupos } \\
\text { de acción como: } \\
\text { - Preservación del medio ambiente } \\
\text { - Calidad de Vida en el Trabajo } \\
\text { - Vinculación con la comunidad } \\
\text { - Ética empresarial }\end{array}$ \\
\hline Femsa & $\begin{array}{l}\text { Femsa es la empresa } \\
\text { integrada de bebidas con un } \\
\text { portafolio de marcas líderes } \\
\text { de cerveza y refrescos. } \\
\text { Incluyendo algunas de las } \\
\text { más importantes áreas } \\
\text { metropolitanas en } \\
\text { América Latina. }\end{array}$ & $\begin{array}{l}\text { - Calidad de vida para sus colaboradores } \\
\text { - Desarrollo comunitario } \\
\text { - Compromiso con el medio ambiente } \\
\text { - Desarrollo económico } \\
\text { - Visión global } \\
\text { - Pacto Mundial }\end{array}$ \\
\hline Bimbo & $\begin{array}{l}\text { Grupo Bimbo es una de las } \\
\text { empresas de panificación } \\
\text { más importantes del mundo } \\
\text { por posicionamiento de } \\
\text { marca, por volumen de } \\
\text { producción y ventas, además } \\
\text { de ser líder en México } \\
\text { y Latinoamérica. }\end{array}$ & $\begin{array}{l}\text { Centra sus acciones de responsabilidad social } \\
\text { en los siguientes rubros: } \\
\text { - Salud } \\
\text { - Medio Ambiente } \\
\text { - Colaboradores } \\
\text { - Sociedad }\end{array}$ \\
\hline
\end{tabular}




\begin{tabular}{|c|c|c|}
\hline Nestlé & $\begin{array}{l}\text { Empresa líder mundial en } \\
\text { Alimentación y Nutrición. } \\
\text { Está presente en todos los } \\
\text { continentes con diversos } \\
\text { productos. }\end{array}$ & $\begin{array}{l}\text { Los campos de acción en los que trabaja son: } \\
\text { - Apoyo al campo } \\
\text { - Apoyo a la comunidad } \\
\text { - Apoyo a la educación } \\
\text { - Apoyo a las instituciones } \\
\text { - Apoyo al cuidado al medio ambiente }\end{array}$ \\
\hline Telmex & $\begin{array}{l}\text { Empresa que ofrece servicios } \\
\text { de telecomunicaciones } \\
\text { y que cuenta con un } \\
\text { constante nivel de } \\
\text { crecimiento en los productos } \\
\text { y servicios que ofrece al } \\
\text { mercado. }\end{array}$ & $\begin{array}{l}\text { Comprometida con el desarrollo de } \\
\text { México mediante siete programas: } \\
\text { - Educación } \\
\text { - Salud } \\
\text { - Justicia } \\
\text { - Desastres Naturales } \\
\text { - Cultura y Desarrollo Humano } \\
\text { - Apoyo al Deporte } \\
\text { - Fundación Centro Histórico, mediante } \\
\text { diversas actividades y donaciones }\end{array}$ \\
\hline HP & $\begin{array}{l}\text { Es la mayor empresa de } \\
\text { tecnologías de la información } \\
\text { del mundo. Fabrica y } \\
\text { comercializa hardware y } \\
\text { software además de brindar } \\
\text { servicios de asistencia } \\
\text { relacionados con la } \\
\text { informática }\end{array}$ & $\begin{array}{l}\text { La empresa le llama a este rubro Ciudadanía Global } \\
\text { HP y comprende: } \\
\text { - Medio ambiente } \\
\text { - Inversión en la comunidad } \\
\text { - Responsabilidad de la cadena de suministro } \\
\text { - Ética empresarial y privacidad }\end{array}$ \\
\hline Sony & $\begin{array}{l}\text { Es una de las compañías } \\
\text { electrónicas más importantes } \\
\text { del mundo, que se ha } \\
\text { expandido en el campo } \\
\text { de la electrónica accediendo } \\
\text { a la producción audiovisual. }\end{array}$ & $\begin{array}{l}\text { Ámbitos de aplicación en Sony de México: } \\
\text { - Calidad de vida en la empresa } \\
\text { - Vinculación de la empresa con la comunidad } \\
\text { - Cuidado y preservación del ambiente } \\
\text { - Ética empresarial }\end{array}$ \\
\hline Microsoft & $\begin{array}{l}\text { Es una empresa multinacional } \\
\text { estadounidense, dedicada } \\
\text { al sector de la informática. } \\
\text { Desarrolla, fabrica, licencia } \\
\text { y produce software para } \\
\text { equipos electrónicos. }\end{array}$ & $\begin{array}{l}\text { Las líneas de Ciudadanía Corporativa están } \\
\text { determinadas desde el corporativo mundial y son las } \\
\text { siguientes: } \\
\text { - Liderazgo responsable } \\
\text { - Promover innovaciones } \\
\text { - Seguridad y privacidad } \\
\text { - Compromiso e inversión en la comunidad } \\
\text { - Respuesta ante desastres y apoyo humanitario }\end{array}$ \\
\hline
\end{tabular}

Fuente: Elaborada por el Centro de Investigación para la Comunicación Aplicada, con base en información: http://www.nestle.com.mx/acerca_nestle/nestle_comunidad.asp ; http://www.walmartmexico.com.mx/ respsoc.html ; http://www.mcdonalds.com.mx/pdf/mcd_irs_2006.pdf; http://www.sabritas.com.mx/empresa_nuestroscompromisos_sociedad.php ; http://www.femsa.com/es/social/ ; http://www.grupobimbo.com/ display.php?section $=6 ;$ http://www.fundaciontelmex.org/fundacion_menu_programas.html ; http://www. hp.com/country/mx/es/companyinfo/globalcitizenship/index.html ; http://www.sony.com.mx/esr/ ; http:// www.microsoft.com/mexico/mscorp/default.mspx ; http://www.microsoft.com/About/CorporateCitizenship/ US/default.mspx 


\section{Los proyectos de responsabilidad social de diez corporaciones líderes en México y algunas notas de prensa que reflejan las percepciones de los periodistas sobre dichas actividades}

A continuación se presentan algunas evidencias del desempeño de diez grupos empresariales (Cuadros 4 y 5 ) en materia de responsabilidad social. Las corporaciones estudiadas son: Wal-Mart, McDonald's, Femsa, Grupo Bimbo, Grupo Telmex, HP, Microsoft, Nestlé, Sabritas y Sony. En primer lugar se presentan las corporaciones que tienen que ver con alimentos y bebidas (Cuadro 4) y en una segunda instancia se presentan aquéllas que tienen que ver con Tecnología (Cuadro 5).

Cuadro 4. Notas de prensa con relación a la responsabilidad social de corporaciones del sector de alimentos y bebidas

\begin{tabular}{|c|c|c|c|}
\hline $\begin{array}{l}\text { Consorcio } \\
\text { responsabilidad } \\
\text { social }\end{array}$ & $\begin{array}{l}\text { Políticas de } \\
\text { Cemefi } \\
\text { ganados }\end{array}$ & $\begin{array}{l}\text { Premios } \\
\text { del } \\
\text { Consorcio }\end{array}$ & Comentarios en la prensa acerca \\
\hline Wal-Mart & $\begin{array}{l}\text { - Actuar conforme } \\
\text { a sus principios } \\
\text { - Buscar el } \\
\text { desarrollo y } \\
\text { calidad de vida } \\
\text { de sus asociados } \\
\text { - Operar } \\
\text { eficientemente } \\
\text { para lograr costos } \\
\text { bajos y ofrecer } \\
\text { precios bajos a } \\
\text { clientes y socios } \\
\text { - Invertir en México } \\
\text { para generar } \\
\text { empleos y } \\
\text { crecimiento para } \\
\text { sus proveedores } \\
\text { - Trabajar con sus } \\
\text { proveedores para } \\
\text { promover la } \\
\text { competitividad } \\
\text { - Privilegiar la } \\
\text { innovación } \\
\text { - Promover el } \\
\text { trabajo voluntario } \\
\text { de sus asociados } \\
\text { - Apoyar la } \\
\text { alimentación } \\
\text { sustentable de las } \\
\text { comunidades }\end{array}$ & 7 premios & $\begin{array}{l}\text { Wal-Mart prepara sus operaciones para } \\
\text { la llegada de Gustav y sirve de modelo en } \\
\text { situaciones de emergencia (Recuperado el } \\
\text { día } 1 \text { de septiembre de 2008. Diario } \\
\text { Reforma online) } \\
\text { Transparentan donativos (Recuperado el día } \\
5 \text { de agosto de 2008. Diario Reforma online): } \\
\text { La gerente de la Fundación Wal-Mart en } \\
\text { México señala que la mayor parte del dinero } \\
\text { que canaliza la empresa a la Fundación } \\
\text { proviene de sus propios recursos. Sólo una } \\
\text { vez al año recurre a una campaña de donación } \\
\text { voluntaria con clientes. } \\
\text { Esconden mexicanas su daño a la } \\
\text { atmósfera (Recuperado el día } 23 \text { de julio } \\
\text { de } 2008 \text {. Diario Reforma online): La nota } \\
\text { comenta que el 80\% de las principales } \\
\text { empresas en México que integran el índice } \\
\text { S\&P40 Latinoamérica, se negaron a revelar } \\
\text { información sobre sus emisiones a la } \\
\text { atmósfera de gases de efecto invernadero } \\
\text { y sus estrategias ante el cambio climático, } \\
\text { pese a que sus accionistas se los solicitaron. } \\
\text { Wal-Mart de México y Cemex sí aceptaron } \\
\text { dar información sobre sus emisiones de } \\
\text { carbono, mientras que empresas como } \\
\text { Femsa, entre otras, hicieron caso omiso } \\
\text { de la petición. }\end{array}$ \\
\hline
\end{tabular}




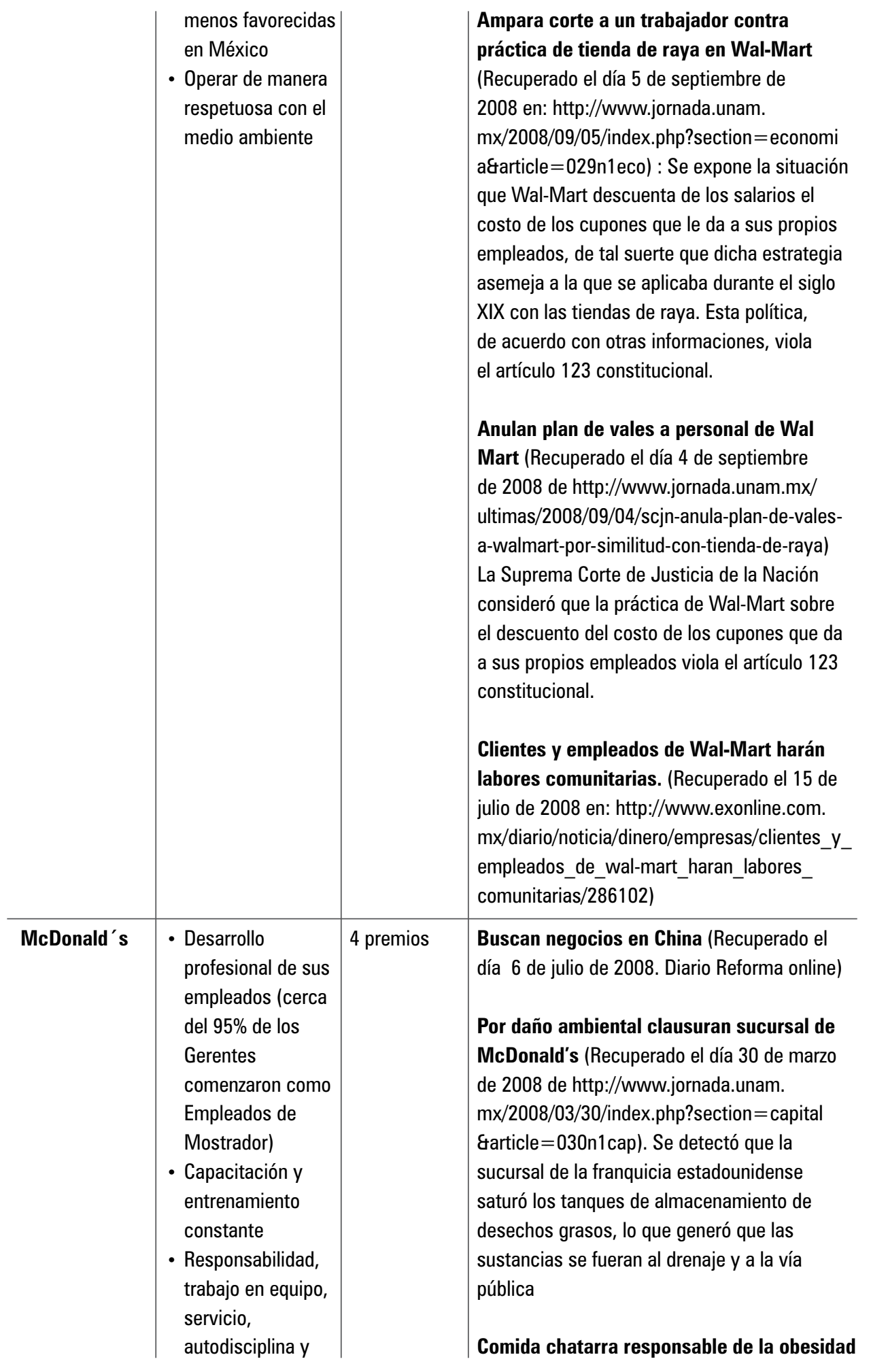




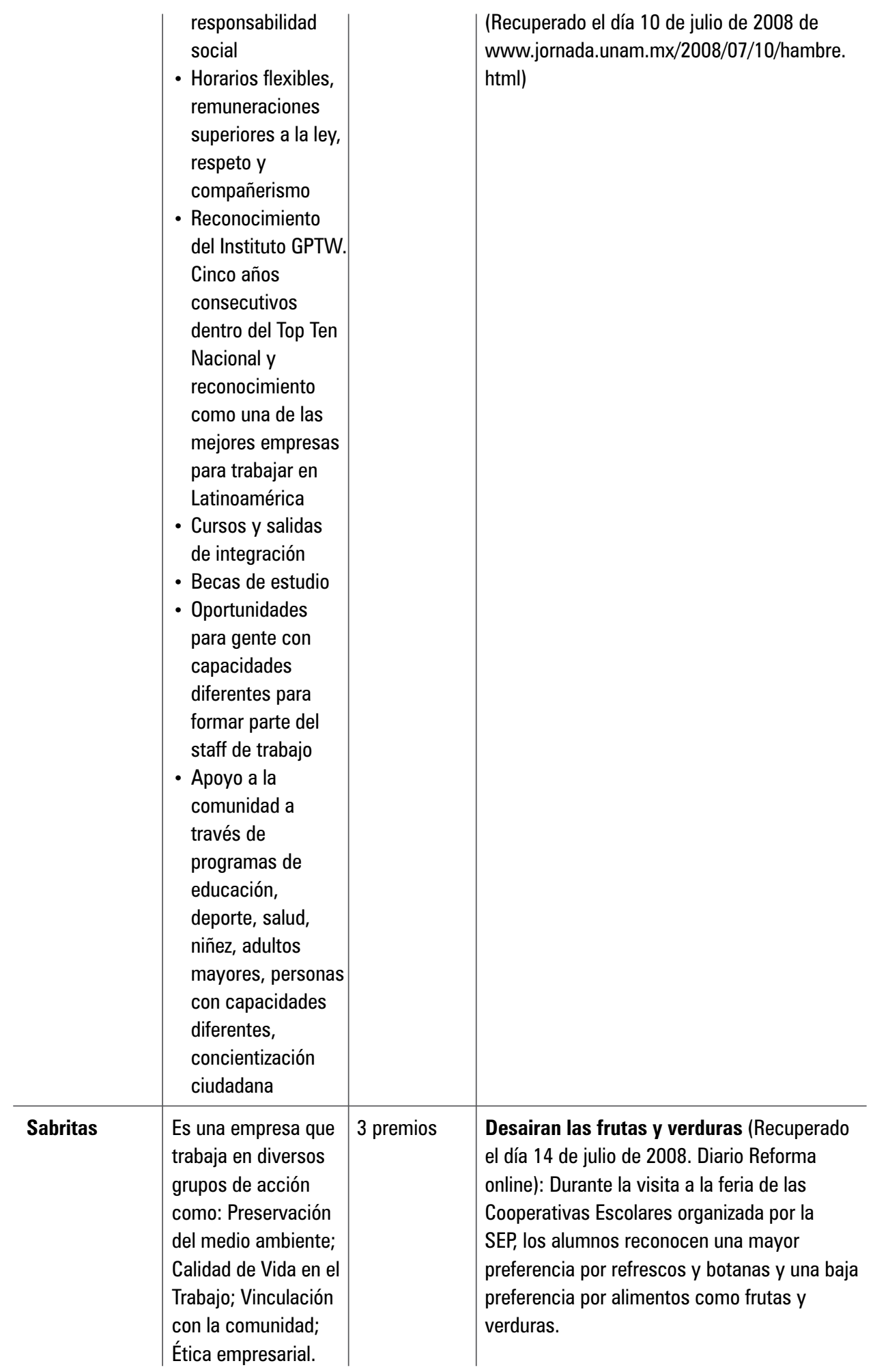

126 POLÍTICAS DE RESPONSABILIDAD SOCIAL Y SUS FORMAS DE DIFUSIÓN DE DIEZ CORPORATIVOS MULTINACIONALES LÍDERES QUE OPERAN EN MÉXICO - MARÍA ANTONIETA REBEIL CORELLA • CLEMENTE SÁNCHEZ URIBE • GUILLERMO LEMUS LEGASPI - MARIANA MORENO MORENO 


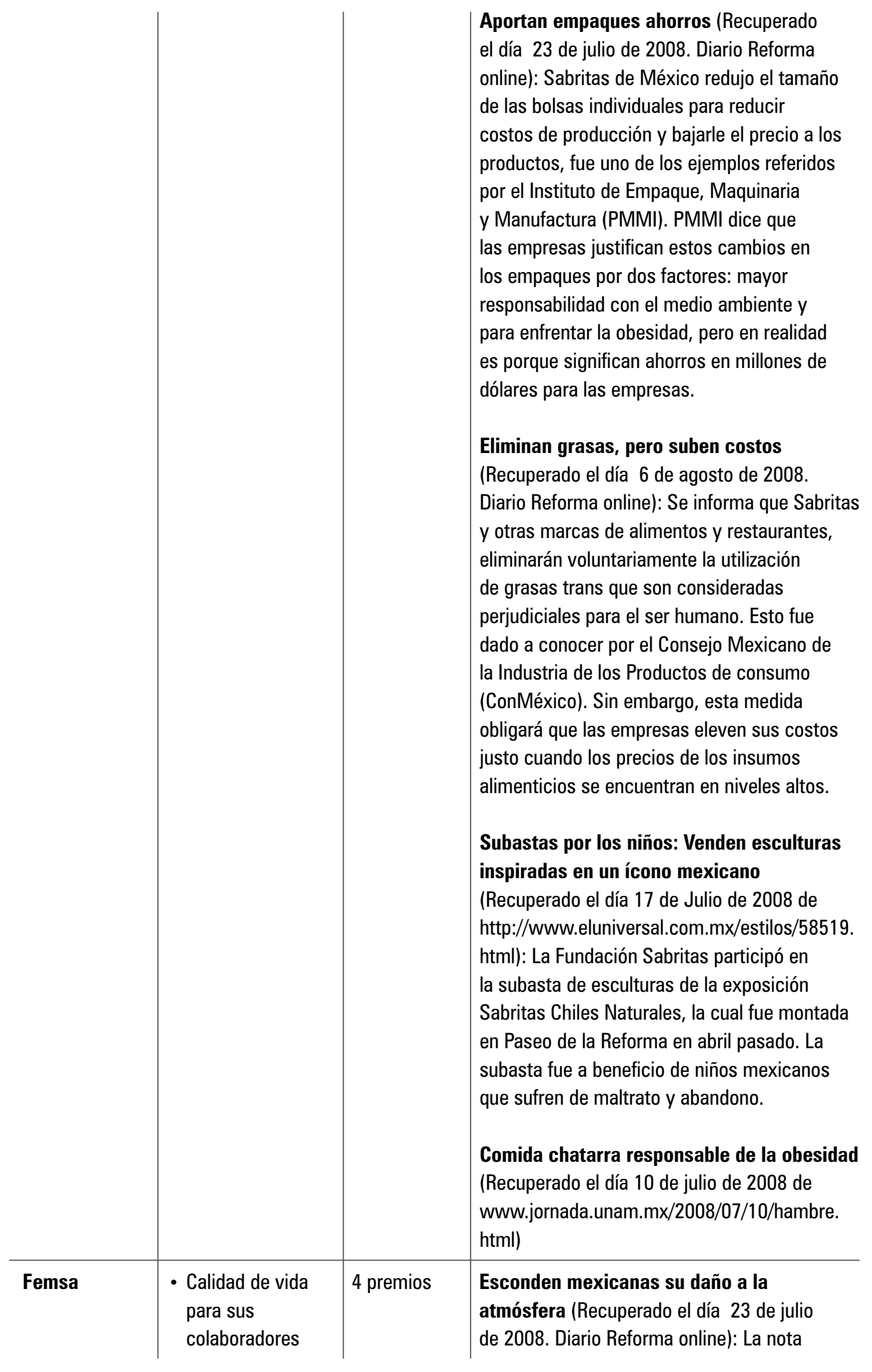

Aportan empaques ahorros (Recuperado el día 23 de julio de 2008. Diario Reforma online): Sabritas de México redujo el tamaño de las bolsas individuales para reducir costos de producción y bajarle el precio a los productos, fue uno de los ejemplos referidos por el Instituto de Empaque, Maquinaria y Manufactura (PMMI). PMMI dice que las empresas justifican estos cambios en los empaques por dos factores: mayor responsabilidad con el medio ambiente y para enfrentar la obesidad, pero en realidad es porque significan ahorros en millones de

Eliminan grasas, pero suben costos (Recuperado el día 6 de agosto de 2008. Diario Reforma online): Se informa que Sabritas eliminarán voluntariamente la utilización de grasas trans que son consideradas perjudiciales para el ser humano. Esto fue dado a conocer por el Consejo Mexicano de la Industria de los Productos de consumo (ConMéxico). Sin embargo, esta medida obligará que las empresas eleven sus costos justo cuando los precios de los insumos alimenticios se encuentran en niveles altos.

Subastas por los niños: Venden esculturas inspiradas en un ícono mexicano (Recuperado el día 17 de Julio de 2008 de http://www.eluniversal.com.mx/estilos/58519. html): La Fundación Sabritas participó en la subasta de esculturas de la exposición Sabritas Chiles Naturales, la cual fue montada en Paseo de la Reforma en abril pasado. La subasta fue a beneficio de niños mexicanos

Comida chatarra responsable de la obesidad (Recuperado el día 10 de julio de 2008 de www.jornada.unam.mx/2008/07/10/hambre. atmósfera (Recuperado el día 23 de julio de 2008. Diario Reforma online): La nota 


\begin{tabular}{|c|c|c|c|}
\hline & $\begin{array}{l}\text { - Desarrollo } \\
\text { comunitario } \\
\text { - Compromiso con } \\
\text { el medio ambiente } \\
\text { - Desarrollo } \\
\text { económico } \\
\text { - Visión global } \\
\text { - Pacto Mundial }\end{array}$ & & $\begin{array}{l}\text { comenta que el } 80 \% \text { de las principales } \\
\text { empresas en México que integran el índice } \\
\text { S\&P40 Latinoamérica, se negaron a revelar } \\
\text { información sobre sus emisiones a la } \\
\text { atmósfera de gases de efecto invernadero } \\
\text { y sus estrategias ante el cambio climático, } \\
\text { pese a que sus accionistas se los solicitaron. } \\
\text { Wal-Mart de México y Cemex aceptaron } \\
\text { dar información sobre sus emisiones de } \\
\text { carbono, mientras que empresas como } \\
\text { FEMSA, entre otras, ignoraron la petición. } \\
\text { Inicia otra lucha entre las "Colas" } \\
\text { (Recuperado el día } 25 \text { de agosto de } 2008 . \\
\text { Diario Reforma online): Se revela que Coca- } \\
\text { Cola manda carta a sus clientes para que no } \\
\text { compren el Big Citrus de Ajemex. Se refirió la } \\
\text { multa de } 15 \text { millones de dólares a Coca-Cola } \\
\text { por prácticas monopólicas y competencia } \\
\text { desleal contra Ajegroup. } \\
\text { Comida chatarra responsable de la obesidad } \\
\text { (Recuperado el día } 10 \text { de julio de } 2008 \text { www. } \\
\text { dejornada.unam.mx/2008/07/10/hambre.html) }\end{array}$ \\
\hline Bimbo & $\begin{array}{l}\text { Centra sus acciones } \\
\text { de responsabilidad } \\
\text { social en los } \\
\text { siguientes rubros: } \\
\text { - Salud } \\
\text { - Medio Ambiente } \\
\text { - Colaboradores } \\
\text { - Sociedad. }\end{array}$ & 8 premios & $\begin{array}{l}\text { Buscan negocios en China (Recuperado el } \\
\text { día } 6 \text { de julio de } 2008 \text {. Diario Reforma online) } \\
\text { Introduce Bimbo empaques "verdes" } \\
\text { (Recuperado el día } 28 \text { de agosto de } 2008 . \\
\text { Diario Reforma on-line) }\end{array}$ \\
\hline Nestlé & $\begin{array}{l}\text { Los campos de } \\
\text { acción en los que } \\
\text { esta empresa trabaja } \\
\text { son: Apoyo al campo, } \\
\text { a la comunidad, a la } \\
\text { educación a las } \\
\text { instituciones y al } \\
\text { cuidado al medio } \\
\text { ambiente. }\end{array}$ & 5 premios & $\begin{array}{l}\text { Comida chatarra responsable de la } \\
\text { obesidad (Recuperado el día } 10 \text { de julio de } \\
2008 \text { de www.jornada.unam.mx/2008/07/10/ } \\
\text { hambre.html) } \\
\text { Derraman productores miles de litros de } \\
\text { leche } \\
\text { (Recuperado el día } 23 \text { de septiembre de } 2008 \\
\text { de http://www.jornada.unam.mx/2008/09/23/ } \\
\text { index.php?section=estados\&rarticle=032n1e } \\
\text { st) Debido al bajo costo que pagan empresas } \\
\text { como Nestlé, los productores se manifestaron } \\
\text { derramando litros de leche en las calles. }\end{array}$ \\
\hline
\end{tabular}

Fuente: Elaborada por el Centro de Investigación para la Comunicación Aplicada, con base en información recopilada vía Internet. Detalle de ligas de enlace: ver ligas referidas en cada noticia. 
La evidencia está presentada de tal manera que el lector logre ver cuáles son los propósitos que la empresa expresa tener con respecto a lograr ser una corporación socialmente responsable y lo que la prensa escrita online manifiesta acerca de las mismas corporaciones.

Mediante ello se pretende que el lector obtenga una visión de las percepciones que la prensa escrita obtenible en la Internet tiene acerca de las operaciones de las mismas corporaciones.

Se llevó a cabo un análisis de notas periodísticas que se encuentran en Internet de algunos periódicos mexicanos: dos de circulación nacional (Reforma y El Universal), así como tres diarios adicionalmente: Milenio (diario nacional), Excélsior (diario nacional) y La Jornada (diario local). La selección de estos medios se basó principalmente en el nivel de impacto y presencia que tienen en la opinión pública nacional, lo cual es importante para conocer el tipo de notas que emiten sobre el tema de referencia de esta investigación. El análisis se dio a partir de un seguimiento de noticias por Internet en dichos medios, por un período de tres meses, a partir de julio $1 \mathrm{y}$ hasta septiembre 30 de 2008. De esta forma, los datos que expresan dichos medios sobre hechos o percepciones de los periodistas, aportan ideas a las propias corporaciones sobre la importancia que tiene la imagen corporativa en temas como la responsabilidad social. De esta manera, es posible comparar que las corporaciones dicen de sí mismas y lo que la prensa dice que hacen en la realidad.

\section{La responsabilidad social en el sector alimentos y bebidas}

En cuanto al conjunto de grupos empresariales que incluyen a las corporaciones: WalMart, McDonald's, Sabritas, Femsa, Bimbo y Nestlé, es posible decir que todas éstas cuentan con propósitos de responsabilidad social claramente expuestos. Algunos de estos Grupos Empresariales hablan de compromisos a nivel internacional tales como el calentamiento global, el agua, medio ambiente y el desarrollo económico (Nestlé, Wal-Mart, Femsa). Otras más, se proponen asumir la responsabilidad ante la sociedad de México, el campo mexicano, la reforestación, la vinculación entre lo urbano y lo rural (Bimbo, Telmex, Sabritas, Wal Mart) (Cuadro 3). Por otra parte, cabe mencionar aquellos casos en los que los propósitos de responsabilidad social se remiten a los actores o públicos internos de la corporación como son sus empleados. Se trata de Bimbo, Femsa, Wal Mart, Sabritas, McDonald's y Sony (Cuadro 3). De acuerdo a sus políticas de responsabilidad social, ésta se inicia en el marco de sus colaboradores más cercanos y en su calidad de vida.

Si se analiza, por otra parte, la cantidad de premios Cemefi de responsabilidad social, también es posible ver que todos los grupos empresariales en la evidencia que se presenta, cuentan con varios de éstos premios, hecho que les acredita formalmente como corporaciones socialmente responsables (tercera columna de los Cuadros 4 y 5). Una mirada alterna a la imagen que tienen estas mismas corporaciones por lo menos ante los formadores de opinión pública, se puede ver en la cuarta columna de los Cuadros 4 y 5. 
Con respecto a los comentarios de la prensa en línea acerca de las operaciones de responsabilidad social de los consorcios en cuestión, es posible decir que Wal-Mart opera con transparencia los donativos que realiza a su propia Fundación Wal-Mart, y por otra parte, ha dado información sobre sus emisiones de carbono de manera constante a la opinión pública. También es notable que tanto clientes como empleados de Wal-Mart, participan en labores comunitarias coordinados por la Corporación. Por otra parte, recientemente la corporación se vio en la necesidad de anular su plan de vales al personal, debido a que la Suprema Corte de Justicia de la Nación consideró que al incluir los vales dentro del monto del salario de sus empleados era una medida anticonstitucional (Cuadro 4).

A su vez, el Consorcio McDonald's se le asocia como probable detonante de la obesidad. Se detectó que una sucursal de esta franquicia, saturó los tanques de almacenamiento de desechos grasos que generó que las sustancias se fueran a la vía pública (Cuadro 4).

Por su parte, el consorcio Sabritas ha llevado a cabo acciones importantes para proteger la salud de sus consumidores. Uno de ellos es la eliminación de las grasas trans de sus productos. No obstante, la prensa hace señalamientos una y otra vez acerca de que el gusto popular prefiere la comida chatarra a las frutas y verduras, cuestión que se relaciona con la creciente obesidad en el país (Cuadro 4). Es importante decir que estos comentarios periodísticos no se refieren única y exclusivamente a los productos de Sabritas, sino a muchos más que impregnan el mercado de las naciones.

La corporación Femsa, a pesar de que emite carbono a la atmósfera, se niega a revelar información acerca de este hecho. Por otra parte, las estrategias promocionales de Coca-Cola han incurrido en prácticas monopólicas desleales contra Big Citrus de Ajemex (Cuadro 4). Cabe señalar que las notas encontradas hablan de manera negativa acerca de la responsabilidad social empresarial de la corporación Femsa. No obstante, habría que considerar si la misma prensa no está omitiendo algunos comentarios positivos acerca de actividades y resultados positivos de responsabilidad social empresarial de esta corporación.

A su vez Bimbo, es una corporación que es coherente con sus políticas de responsabilidad social empresarial al elaborar "empaques verdes" y buscar expandir sus productos y filosofía hacia los países asiáticos (Cuadro 4).

La empresa Nestlé que tiene como una de sus políticas el apoyar al campo, se vio relacionada con una protesta por parte de los productores de leche, debido al bajo costo que pagan por el producto (Cuadro 4).

En resumen se puede decir que mientras algunas corporaciones son coherentes con los principios de responsabilidad social que ellos mismos se han impuesto, algunas otras incurren en ocasiones, de manera indirecta, en contradicciones al respecto de la responsabilidad social. Con ello se desea recalcar la gran dificultad que existe entre desear ser socialmente responsable y proponérselo formalmente, y por otra parte 
llevarlo a la práctica. Muchas de estas cuestiones tienen que ver con los altos costos que implica el poner las condiciones para desintegrar desechos, pagar salarios y prestaciones justas, atender con eficiencia y buenos precios a los proveedores.

\section{La responsabilidad social en el sector tecnología y telecomunicaciones}

A continuación se presentan algunas corporaciones líderes en México que tienen que ver con tecnología y con telecomunicaciones: Telmex, HP, Sony y Microsoft (Cuadro 5). Las cuatro corporaciones denotan tener propósitos claramente encaminados hacia la responsabilidad social, HP y Sony distinguiéndose por la preocupación que manifiestan hacia sus empleados y sus clientes. Sony, además, señala sus propósitos hacia del medio ambiente y la ética empresarial. Telmex, tiene una clara vocación de empresa mexicana con motivos vinculados a los problemas estructurales del país. Microsoft, por su parte, busca ser socialmente responsable a través del incremento de la interconectividad en México y que ésta se dé en los menores costos posibles. Igual que el caso anterior, estas corporaciones cuentan con varios reconocimientos por parte del Cemefi (Cuadro 5).

No obstante, Telmex ha logrado reducir las quejas ante la Procuraduría Federal del Consumidor en un $73 \%$. Con ello, se tiene un indicador substancial de que está siendo socialmente responsable ante sus clientes. De acuerdo a la Comisión Federal de Telecomunicaciones, así como la Comisión Federal de Competencia y la Canitec, señalan a Telmex como realizador de actividades de competencia desleal con otras empresas similares. Es importante señalar que Telmex busca lograr la interconectividad de México en su conjunto y de los otros países en los que opera. La tendencia de la empresa a ser responsable frente a sus clientes ha tenido logros importantes. La pregunta que permanece es ¿cómo ser socialmente responsable y al mismo tiempo llevar a cabo las actividades de competencia frente a empresas similares con cuyos intereses se entra en conflicto? En verdad, es una pregunta muy difícil de responder y habría que ponerla a consideración de un foro amplio de pensadores y profesionales (Cuadro 5).

En cuanto al consorcio HP es posible decir que la empresa, de acuerdo a las notas de empresa, muestra apertura para la integración de nuevos empleados. Por otra parte, se habla de cómo esta corporación está vinculada al sector educativo a través de premios a las mejores prácticas de enseñanza y aprendizaje (Cuadro 5).

Con respecto a Sony y sus labores de responsabilidad social empresarial es posible decir que ha tenido actividades de responsabilidad frente a sus clientes, ya que reconoció falla en uno de sus productos y lo retiró del mercado para su reparación. Por otra parte, más allá de atender a sus clientes, Sony se involucra con actividades que tienen que ver con el apoyo a personas con cáncer (Cuadro 5).

Con respecto a las empresas de Sony y Microsoft se encontró una nota de la organización Greenpeace que señala que el hardware de Sony, Microsoft y Nintendo contienen contaminantes tóxicos y que al descartar estos en los tiraderos de países como 
China y México, resultan en fuentes adicionales de intoxicación (Cuadro 5).

Respecto a las empresas de telecomunicaciones y electrónica, es posible señalar que la prensa no ha logrado captar la totalidad de sus emprendimientos en cuanto a responsabilidad social se refiere. Se tiene conocimiento de la amplitud de las acciones que han alcanzado empresas tales como Telmex, a través de la Fundación Centro Histórico y otras.

Las notas periodísticas en este caso se basan en evidencias empíricas y pueden estar señalando a problemas reales que distan de reforzar los propósitos de responsabilidad social con la cual estas corporaciones manifiestan estar comprometidas (Cuadro 5).

Cuadro 5. Notas de prensa con relación

a la responsabilidad social de corporaciones

del sector tecnología y telecomunicaciones

\begin{tabular}{|c|c|c|c|}
\hline Consorcio & $\begin{array}{l}\text { Políticas de } \\
\text { responsabilidad } \\
\text { social }\end{array}$ & $\begin{array}{l}\text { Premios } \\
\text { Cemefi } \\
\text { ganados }\end{array}$ & $\begin{array}{l}\text { Comentarios en la prensa acerca } \\
\text { del Consorcio }\end{array}$ \\
\hline Telmex & $\begin{array}{l}\text { Comprometida con el } \\
\text { desarrollo de México } \\
\text { mediante siete } \\
\text { programas: } \\
\text { Educación, Salud, } \\
\text { Justicia, Desastres } \\
\text { Naturales, Cultura } \\
\text { y Desarrollo Humano, } \\
\text { Apoyo al Deporte } \\
\text { y Fundación Centro } \\
\text { Histórico, mediante } \\
\text { diversas actividades } \\
\text { y donaciones. }\end{array}$ & 7 premios & $\begin{array}{l}\text { Telmex redujo sus quejas en Profeco en un } \\
\text { 73\% (Recuperado el día } 3 \text { de Julio de } 2008 \text { de } \\
\text { http://www.eluniversal.com.mx/finanzas/ } \\
65211 . h t m l \text { ) } \\
\text { Cofetel: problemas con la competencia de } \\
\text { Telmex (Recuperado el día } 8 \text { de Julio de } 2008 \\
\text { de http://www.eluniversal.com.mx/ } \\
\text { columnas/72419.html) } \\
\text { Fallas en las redes telefónicas (Recuperado } \\
\text { el día } 14 \text { de Julio de } 2008 \text { de http://www. } \\
\text { eluniversal.com.mx/finanzas/65401.html) } \\
\text { Reporta Telmex llamadas perdidas } \\
\text { (Recuperado el día } 16 \text { de Julio de } 2008 \text { de http:// } \\
\text { www.eluniversal.com.mx/finanzas/65438.html) } \\
\text { Esconden mexicanas su daño a la atmósfera } \\
\text { (Recuperado el día } 23 \text { de julio de } 2008 \text {. Diario } \\
\text { Reforma on-line): La nota comenta que el } 80 \% \text { de } \\
\text { las principales empresas en México que integran } \\
\text { el índice S\&P40 Latinoamérica, se negaron a } \\
\text { revelar información sobre sus emisiones a la } \\
\text { atmósfera de gases de efecto invernadero y sus } \\
\text { estrategias ante el cambio climático, pese a } \\
\text { que sus accionistas se los solicitaron. Wal-Mart }\end{array}$ \\
\hline
\end{tabular}




\begin{tabular}{|c|c|c|c|}
\hline & & & $\begin{array}{l}\text { de México y Cemex aceptaron dar información } \\
\text { sobre sus emisiones de carbono, mientras que } \\
\text { empresas como Telmex, Femsa, entre otras, } \\
\text { ignoraron la petición. } \\
\text { Telmex perjudica al consumidor e inhibe la } \\
\text { competencia: CFC (Recuperado el día } 26 \text { de } \\
\text { Julio de } 2008 \text { en: http://www.eluniversal.com. } \\
\text { mx/nacion/161240.html) } \\
\text { Deslealtad en la portabilidad, pierde Telmex } \\
7800 \text { clientes (Recuperado el día } 8 \text { de Agosto } \\
\text { de } 2008 \text { en: http://www.eluniversal.com.mx/ } \\
\text { finanzas/66228.html) } \\
\text { Telmex "pretende confundir" a la opinión } \\
\text { pública, asegura Canitec. (Recuperado el } 10 \\
\text { de julio de 2008 en: http://www.milenio.com/ } \\
\text { node/45382) }\end{array}$ \\
\hline HP & $\begin{array}{l}\text { La empresa le llama } \\
\text { a este rubro } \\
\text { Ciudadanía Global HP } \\
\text { y comprende: } \\
\text { - Medio ambiente } \\
\text { - Inversión en la } \\
\quad \text { comunidad } \\
\text { - Responsabilidad } \\
\text { de la cadena de } \\
\text { suministro } \\
\text { - Ética empresarial } \\
\text { y privacidad }\end{array}$ & 8 premios & $\begin{array}{l}\text { HP premia proyecto de la UVM para una } \\
\text { mejor enseñanza - aprendizaje (Recuperado } \\
\text { el día } 11 \text { de Agosto de } 2008 \text { de http://www. } \\
\text { eluniversal.com.mx/articulos/48441.html) } \\
\text { Completa HP adquisición de EDS por } 13 \text { mil } \\
900 \text { mdd (Recuperado el día } 26 \text { de Agosto de } \\
2008 \text { en: http://www.eluniversal.com.mx/ } \\
\text { articulos/48813.html) }\end{array}$ \\
\hline Sony & $\begin{array}{l}\text { Ámbitos de aplicación } \\
\text { en Sony de México: } \\
\text { - Calidad de vida en } \\
\text { la empresa } \\
\text { - Vinculación de la } \\
\text { empresa con la } \\
\text { comunidad } \\
\text { - Cuidado y } \\
\text { preservación del } \\
\text { ambiente } \\
\text { - Ética empresarial }\end{array}$ & 2 premios & $\begin{array}{l}\text { Greenpeace descubre a Sony, Microsoft y } \\
\text { Nintendo jugando sucio (Recuperado en } \\
\text { agosto de } 2008 \text { en: http://www.greenpeace. } \\
\text { org/mexico/news/greenpeace-descubre-a } \\
\text {-sony-mi) } \\
\text { Subastan papel, para apoyar enfermos } \\
\text { de cáncer (Recuperado el día } 30 \text { de Agosto de } \\
2008 \text { en: http://www.eluniversal.com.mx/ } \\
\text { espectaculos/85214.html): Sony está } \\
\text { subastando por Internet la participación en } \\
\text { un pequeño "papel" de extra para la cuarta parte } \\
\text { de la película Spiderman. Esta subasta es con } \\
\text { fines benéficos a favor de la fundación contra el } \\
\text { cáncer Stand up to Cancer. }\end{array}$ \\
\hline
\end{tabular}




\begin{tabular}{|c|c|c|c|}
\hline & & & $\begin{array}{l}\text { Llama Sony a revisión } 440 \text { mil laptops Vaio } \\
\text { TZ (Recuperado el día } 4 \text { de Septiembre de } \\
2008 \text { en: http://www.eluniversal.com.mx/ } \\
\text { articulos/49050.html) Debido a un defecto de } \\
\text { recalentamiento, siete personas han resultado } \\
\text { heridas desde agosto 2007. La empresa } \\
\text { reconoció su falla y retiró los equipos para su } \\
\text { reparación. }\end{array}$ \\
\hline Microsoft & $\begin{array}{l}\text { Las líneas de } \\
\text { Ciudadanía } \\
\text { Corporativa están } \\
\text { determinadas desde } \\
\text { el corporativo } \\
\text { mundial y son las } \\
\text { siguientes: } \\
\text { - Liderazgo } \\
\text { responsable } \\
\text { - Promover } \\
\text { innovaciones } \\
\text { - Seguridad y } \\
\text { privacidad } \\
\text { - Compromiso e } \\
\text { inversión en la } \\
\text { comunidad } \\
\text { - Respuesta ante } \\
\text { desastres y apoyo } \\
\text { humanitario }\end{array}$ & 4 premios & $\begin{array}{l}\text { Greenpeace descubre a Sony, Microsoft y } \\
\text { Nintendo jugando sucio (Recuperado en } \\
\text { agosto de } 2008 \text { en: http://www.greenpeace. } \\
\text { org/mexico/news/greenpeace-descubre } \\
\text {-a-sony-mi) }\end{array}$ \\
\hline
\end{tabular}

Fuente: Elaborada por el Centro de Investigación para la Comunicación Aplicada, con base en información recopilada vía Internet. Detalle de ligas de enlace: ver ligas referidas en cada noticia.

\section{Difusión de las actividades de responsabilidad social por parte de las corporaciones en el estudio}

Las formas de difusión que emplean las corporaciones en el estudio y la inversión que realizan en el proceso de dar a conocer sus proyectos de responsabilidad social son muy variadas. Pero es importante señalar el empleo de las nuevas tecnologías como lo es el Internet para colocar áreas especiales que permitan abordar las temáticas de responsabilidad social de las corporaciones, incluyendo por supuesto los informes anuales, que bien pueden denotar una intención de transparentar los esfuerzos en torno a esta temática. De aquí que la segunda parte de la labor es de la comunidad al poder consultar estos documentos y corroborar que la teoría coincida con las prácticas.

Sin embargo, y aunque se puede reconocer el uso de nuevas tecnologías, se puede percibir que la materia de responsabilidad social resulta muy nueva para las corporaciones, desde el no uso de un código de términos que denoten las mismas ideas hacia 
el público lector. Por ejemplo, diversas corporaciones que aparecen en el presente escrito sí manejan la sección de su página de Internet como Responsabilidad Social, pero hay otras que para hablar del rubro, hay que acceder a través de la Fundación de la propia corporación (por ejemplo Telmex). Esta situación implica aparentemente limitar el alcance del término en sí mismo, ya que a través de ser canalizados por la Fundación, podría tenerse la idea de que la corporación sólo emplea la responsabilidad social como algo relacionado a filantropía, y no necesariamente se orienta hacia su público interno. Por otro lado, están los grupos empresariales que invierten no solamente en difundir informes de sus actividades, sino que realizan campañas a través de medios masivos para extender el impacto de sus actividades de responsabilidad social. Al respecto se pueden mencionar las Campañas de Redondeo y de Conductor Designado de Femsa; las actividades en el medio televisivo, la difusión de tips de mejora de hábitos nutritivos y las motivaciones para que la población haga ejercicio en las envolturas de los productos de Bimbo; la Casa Telmex para fomentar la interacción de niños con la tecnología, la dotación de becas a los mejores promedios mexicanos, la reconstrucción del Centro Histórico son proyectos ampliamente difundidos en la sociedad Mexicana (Telmex) (Cuadro 5).

Así mismo, Sabritas y Nestlé cuentan con un marco amplio de difusión de sus esfuerzos por mejorar los hábitos alimenticios de sus consumidores, así como de sus proyectos educativos como Iniciativa Nutrir de Nestlé y la Casa Hogar Oasis de la Niñez de Sabritas. Algo significativo es que las corporaciones consideradas en este trabajo, en su mayoría consideran al Internet como una herramienta de gran importancia para difundir sus actividades de responsabilidad social, y prueba de ello es el diseño, secciones y temáticas de sitios como Femsa, Sabritas, Wal-Mart, o Nestlé. Sin embargo, tenemos otros casos como el de Microsoft donde no ha sido desarrollado un sitio de Ciudadano Corporativo Responsable en español, sino las secciones referidas al rubro de responsabilidad social empresarial se ligan a las páginas Internet del corporativo mundial en inglés. Esto podría hablar de una homologación de criterios a nivel mundial lo cual es bueno, aunque limita el acceso de la gente que no domine o no maneje dicho idioma; y por otro lado, McDonald's, cuya sección de responsabilidad social está orientada primordialmente a presentar enlaces que permiten descargar los archivos que corresponden a los Informes de Responsabilidad Social de 2006, 2005 y 2003 (Cuadro 6).

Cuadro 6. Formas de difusión de las actividades de responsabilidad social de diez corporaciones multinacionales que operan en México

\begin{tabular}{l|l|l}
\hline Grupos & Tácticas de Comunicación & Forma de difusión \\
\hline Wal-Mart & $\begin{array}{l}\text { 1. Informe anual de responsabilidad } \\
\text { social } \\
\text { 2. Fundación Wal-Mart de México } \\
\text { 3. Programas de sustentabilidad }\end{array}$ & $\begin{array}{l}\text { 1.Sección de Responsabilidad social } \\
\text { dentro de la página de Internet de } \\
\text { Wal-Mart de México corporativa }\end{array}$ \\
\hline
\end{tabular}




\begin{tabular}{|c|c|c|}
\hline McDonald's & $\begin{array}{l}\text { 1. Informe anual de Responsabilidad } \\
\text { Social } \\
\text { 2. Informe de donaciones realizadas }\end{array}$ & $\begin{array}{l}\text { 1. Sección de Responsabilidad social } \\
\text { dentro de la página de Internet de } \\
\text { McDonald's México corporativa } \\
\text { 2. Publicadas en la prensa y en internet }\end{array}$ \\
\hline Sabritas & $\begin{array}{l}\text { 1. Reporte de compromisos asumidos } \\
\text { con la sociedad y medio ambiente } \\
\text { 2. Informe de apoyo a Casa Hogar el } \\
\text { Oasis de la Niñez } \\
\text { 3. Fundación Sabritas }\end{array}$ & $\begin{array}{l}\text { 1. Sección denominada Nuestros } \\
\text { compromisos con la sociedad dentro } \\
\text { de la página de Internet de Sabritas } \\
\text { México corporativa (ahí se incluye un } \\
\text { subapartado denominado responsabilidad } \\
\text { social) } \\
\text { 2. Publicación de notas/entrevistas } \\
\text { en la prensa }\end{array}$ \\
\hline Femsa & $\begin{array}{l}\text { 1. Calidad de vida para sus } \\
\text { colaboradores } \\
\text { 2. Desarrollo comunitario / compromiso } \\
\text { ambiental y desarrollo económico } \\
\text { 3. Comunicados de eventos de } \\
\text { Responsabilidad Social }\end{array}$ & $\begin{array}{l}\text { 1. Campaña publicitaria por toda la } \\
\text { República, medios de comunicación } \\
\text { masiva } \\
\text { 2. Campaña por televisión } \\
\text { 3. Sección de Responsabilidad social } \\
\text { dentro de la página de Internet de Femsa } \\
\text { México corporativa }\end{array}$ \\
\hline Bimbo & $\begin{array}{l}\text { 1. Informe anual de responsabilidad } \\
\text { social } \\
\text { 2. Programa "Comprometidos con tu } \\
\text { Salud" } \\
\text { 3. Informe de comprometidos con el } \\
\text { Medio Ambiente } \\
\text { 4. Informe de "Reforestamos México" }\end{array}$ & $\begin{array}{l}\text { 1. Sección de Responsabilidad social } \\
\text { dentro de la página de Internet de Grupo } \\
\text { Bimbo México corporativa } \\
\text { 2.Comerciales televisivos, anuncios en } \\
\text { radio y envolturas (realizar } 30 \text { min } \\
\text { ejercicio) } \\
\text { 3. Impresiones y correos electrónicos } \\
\text { 4. Publicación de sus actividades } \\
\text { relacionadas con el medio ambiente }\end{array}$ \\
\hline Nestlé & $\begin{array}{l}\text { 1. Informe anual de Responsabilidad } \\
\text { Social } \\
\text { 2. Iniciativa Nutrir - Sección: Un sano } \\
\text { vivir es posible todos los días - } \\
\text { Nutrición Nestlé } \\
\text { 3. Iniciativa Recetas para sacar el } \\
\text { sabor de la vida - Cocina Nestlé }\end{array}$ & $\begin{array}{l}\text { 1. Sección de Nestlé en la comunidad } \\
\text { dentro de la página de Internet de Nestlé } \\
\text { México corporativa }\end{array}$ \\
\hline Telmex & $\begin{array}{l}\text { 1. Informe anual de Responsabilidad } \\
\text { Social } \\
\text { Informe y difusión de: } \\
\text { 2. Casa Telmex } \\
\text { 3. Fundación Telmex (Becas) } \\
\text { 4. Los diversos de programas que } \\
\text { apoyan en cirugías, justicia y } \\
\text { desastres naturales }\end{array}$ & $\begin{array}{l}\text { 1. Sección de Fundación Telmex dentro } \\
\text { de la página de Internet de Telmex } \\
\text { corporativa } \\
\text { 2. Sitios virtuales donde los niños } \\
\text { interactúan con la tecnología } \\
\text { 3. Vinculo con las universidades para } \\
\text { elegir los mejores promedios, } \\
\text { http://www.escom.ipn.mx/contenidos/ } \\
\text { telmex.jsp se observa los formatos } \\
\text { de solicitud }\end{array}$ \\
\hline
\end{tabular}

136 POLÍTICAS DE RESPONSABILIDAD SOCIAL Y SUS FORMAS DE DIFUSIÓN DE DIEZ CORPORATIVOS MULTINACIONALES LÍDERES OUE OPERAN EN MÉXICO - MARía ANTONIETA REBEIL CORELLA • CLEMENTE SÁNCHEZ URIBE • GUILLERMO LEMUS LEGASPI • MARIANA MORENO MORENO 


\begin{tabular}{l|l|l} 
& & $\begin{array}{l}\text { 4. Cuentan con publicaciones en página } \\
\text { oficial y en noticias periodísticas acerca } \\
\text { de los resultados }\end{array}$ \\
\hline HP & $\begin{array}{l}\text { 1. Folleto de ciudadanía global de HP } \\
\text { 2. Reporte de ciudadanía global HP } \\
\text { 3. Reporte de clientes de ciudadanía } \\
\text { global de HP México }\end{array}$ & $\begin{array}{l}\text { 1. Sección de Ciudadanía global de } \\
\text { HP dentro de la página de Internet } \\
\text { de HP de México corporativa }\end{array}$ \\
\hline Sony & $\begin{array}{l}\text { 1. Informe anual de Responsabilidad } \\
\text { Social y datos informativos sobre } \\
\text { sus actividades en este rubro }\end{array}$ & $\begin{array}{l}\text { 1. Sección de Responsabilidad social } \\
\text { dentro de la página de Internet de Sony } \\
\text { de México corporativa (página } \\
\text { informativa) }\end{array}$ \\
\hline Microsoft & $\begin{array}{l}\text { 1. Informe de actividades de } \\
\text { responsabilidad social }\end{array}$ & $\begin{array}{l}\text { 1. Sección Corporate Citizenship en la } \\
\text { página Internet del corporativo mundial } \\
\text { de Microsoft EEUU. La página Internet } \\
\text { de México se enlaza directamente } \\
\text { al corporativo mundial }\end{array}$ \\
\hline
\end{tabular}

Fuente: Elaborada por el Centro de Investigación para la Comunicación Aplicada, con base en información: http://www.nestle.com.mx/acerca_nestle/nestle_comunidad.asp ; http://www.walmartmexico.com.mx/ respsoc.html ; http://www.mcdonalds.com.mx/pdf/mcd_irs_2006.pdf; http://www.sabritas.com.mx/empresa_nuestroscompromisos_sociedad.php ; http://www.femsa.com/es/social/ ; http://www.grupobimbo.com/ display.php?section $=6 ;$ http://www.fundaciontelmex.org/fundacion menu programas.html ; http://www. hp.com/country/mx/es/companyinfo/globalcitizenship/index.html ; http://www.sony.com.mx/esr/ ; http:// www.microsoft.com/mexico/mscorp/default.mspx ; http://www.microsoft.com/About/CorporateCitizenship/ US/default.mspx

\section{Conclusiones}

La ética empresarial que considera la centralidad y dignidad de la persona humana resulta medular y la idea fundamental que sustenta las razones, los propósitos y las acciones de responsabilidad social en las corporaciones de todo tipo.

$\mathrm{Al}$ respecto, el trabajo sustenta que las actividades de responsabilidad social en las corporaciones en general, deben tener como idea central la prioridad de las personas sobre las ganancias económicas. Por lo que, los cuatro actores con los que interactúa toda corporación: clientes, empleados, sociedad y socios, y las acciones de responsabilidad social que se realizan para estos públicos, y la obtención de ganancias para el consorcio pueden y deben ir de la mano. Esto incluso ha generado bases importantes que plasman estos aspectos. Un ejemplo puede ser el Código de Conducta para Empresas Multinacionales, adoptado desde noviembre de 1977 por los miembros de la Corporación Internacional del Trabajo (OIT)².

El análisis de las diez corporaciones en el estudio señala que aunque todas éstas cuen-

2 LÓPEZ, G. La responsabilidad social de las empresas y el clima laboral. Disponible en: http://www.bibliojuridica.org/libros/5/2458/18.pdf. 
tan con propósitos definidos de responsabilidad social, la mayoría los enfocan hacia sus públicos inmediatos tales como sus empleados y clientes. Otras más, las menos, consideran a la responsabilidad social como el terreno de las acciones aledañas y separadas de sus procesos operativos y de producción.

Por otro lado, la prensa online no siempre favorece a estas corporaciones en la formación de una imagen positiva de éstos conglomerados y en ocasiones hasta les acusa de realizar actividades que ponen en entredicho su actuar para con sus públicos inmediatos: clientes y empleados, así como en la sociedad.

La extensión y la amplitud de los esfuerzos de responsabilidad social que las diez corporaciones realizan varían substancialmente. En algunos casos como Bimbo, Sabritas, Femsa, Nestlé, Telmex la responsabilidad social es parte de su diario acontecer y se podría decir que sus esfuerzos por obtener ganancias económicas van a la par de sus propósitos sociales y educativos. Para otras corporaciones, aparentemente sus actividades de responsabilidad social se manejan como un apartado de su vida cotidiana. Casi se podría decir que no han acabado de incorporar en su DNA estas actividades que lejos de debilitarlas, les aportan la legitimidad que requieren para su desempeño en la sociedad.

La responsabilidad social empresarial aun tiene un largo camino por recorrer en el marco de esta sociedad mexicana, así como en el contexto de otras realidades. Es alentador analizar que muchas corporaciones de la mayor importancia en México ya están conscientes de ello y que algunas de estas corporaciones van dando pasos relevantes en el marco de la aportación de elementos para la mejora de sus ambientes laborales, así como educativos y de salud para sus clientes, y culturales para sus distintos públicos: clientes, empleados y la sociedad. De acuerdo con datos de Cemefi, con base en su entrega de Distintivos a Empresas Socialmente Responsables (ESR) 2008, en este año dicho reconocimiento se entregó a 273 compañías, 57\% más con respecto al año inmediato anterior (MORENO, 2008).

Sin embargo, las corporaciones en México deben estar concientes de que la responsabilidad social no se circunscribe a un período determinado. Se trata más bien de una cultura que debe permear y ser parte de las operaciones de la organización a lo largo de su vida.

Un caso concreto que resulta trascendente mencionar, y que sin duda dará ocasión para un nuevo trabajo reflexivo y de investigación sobre este tema, es el análisis de que en las últimas semanas se han generado diversas notas de prensa por Internet, que se refieren al tema del retorno de migrantes mexicanos a causa de la crisis económica que enfrenta los Estados Unidos. ¿Cómo se está preparando México y otros países para que sus corporaciones respondan de manera eficiente y socialmente responsable, tanto a sus empleados actuales como a los nuevos que tienen que recibir?

Por otra parte, es preciso también preguntarse: ¿Cómo pueden los procesos de comunicación dentro de los corporativos coadyuvar a la comprensión y a la práctica del verdadero sentido de la responsabilidad social? 


\section{Referencias}

BELAUSTEGUIGOITIA, I. Empresas familiares y responsabilidad social en México. Recuperado en: agosto/2008. Disponible en: http://cedef.itam.mx/PDF/empresasfamiliaresyresponsabilidad\%20socialenmexico.pdf

CAJIGA, J.F. Fundamentos de la RSE. Centro Mexicano para la Filantropìa A.C. Recuperado en: agosto/2008. Disponible en: http://www.cemefi.org/spanish/content/view/632/19\#_ftn2

CORTINA, A. La ética de las organizaciones sanitarias. Revista gerencia y políticas de salud, año/vol. 1, número 003, Pontificia Universidad Javeriana, 2002, pp. 6-14.

CRESPO, M. Lo ético de la ética empresarial. Revista Venezolana de Gerencia, abril-junio, año/vol. 8, número 022, Universidad del Zulia, 2003, pp. 307-322.

FERRER, J. Responsabilidad y códigos de ética, conjunción ineludible en la construcción de organizaciones humanas para la gestión pública: un caso de aplicación. Ponencia presentada en VII Congreso Internacional del CLAD sobre la Reforma del Estado y de la Administración Pública, Lisboa, Portugal, 8/11 0ct., 2002.

GALINDO, A. Nuevos ámbitos de responsabilidad social de la empresa desde el "tercer sector" a la economía de comunión. Papeles de Ética, Economía y Dirección, n 8, Universidad Pontificia de Salamanca, 2003, pp. 1-19.

GONZÁLEZ, M. Empresas sin responsabilidad social. México: La Gaceta/ UDG, 2007. Recuperado en agosto de 2008. Disponible en: http://www.gaceta.udg.mx/Hemeroteca/paginas/483/483-7.pdf

Organización Greenpeace. Recuperado en agosto de 2008. Disponible en: http://www.greenpeace.org/mexico/

HIDALGO, J. Empresas mediáticas de fuente abierta: la transformación organizacional en la Era del Entretenimiento. Documento de discusión elaborado para el Centro de Investigación para la Comunicación Aplicada (CICA), de la Escuela de Comunicación de la Universidad Anáhuac. México, 2008.

.Ética aplicada en la empresa. Documento de discusión realizado para Liderazgo de Acción Positiva. Anáhuac, México Norte, 2007

.Ética en la comunicación empresarial. Documento de discusión realizado para Liderazgo de Acción Positiva. Anáhuac, México Norte, 2007.

. La centralidad de la persona en el mundo del trabajo. Documento de discusión realizado para Liderazgo de Acción Positiva. Anáhuac, México Norte, 2007.

¿Cómo elaborar un estudio de caso? Documento de discusión realizado para Liderazgo de Acción Positiva. Anáhuac, México Norte, 2008.

. La dimensión antropológica de la ética empresarial. Documento de discusión realizado para Liderazgo de Acción Positiva. Anáhuac, México Norte, 2008.

INEGI. Encuesta Nacional sobre Población Económicamente Activa.

LÓPEZ, G. La responsabilidad social de las empresas y el clima laboral. México: Biblioteca Jurídico Virtual del Instituto de Investigaciones Jurídicas de la UNAM. Recuperado en agosto de 2008. Disponible en: http://www.bibliojuridica.org/ libros/5/2458/18.pdf

MARCO, G. Ética y liderazgo empresarial: una complementariedad necesaria. Papeles de Ética, Economía y Dirección, n 5 , Universidad de Valencia, 2000, pp. 1- 14.

MELÉ, D. Ética empresarial: enseñanzas clave de la iglesia Católica. Documento de discusión elaborado para IESE, Occasional Paper de la Universidad de Navarra. España, 2004.

Políticas de ética empresarial: posibilidades y limitaciones. Papeles de Ética, Economía y Dirección, n 5, Universidad de Navarra, 2000, pp. 1-17.

. Un marco humanista para la empresa del siglo XXI, IESE, 2001, pp. 1-15.

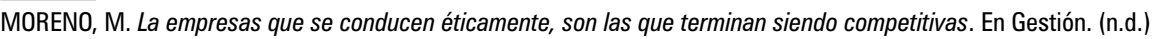

MORENO, T. Responsabilidad social aumenta en México. Recuperado en agosto de 2008. Disponible en: http://www.cnnexpansion. com/emprendedores/2008/03/12/responsabilidad-social-aumenta-en-mexico.

REBEIL, M.A. (Coord.) Comunicación estratégica en las organizaciones. México: Editorial Trillas, 2008.

REGALADO, R. Las MIPYMES en Latinoamérica. Recuperado en agosto de 2008. Disponible en: http://www.eumed.net/ libros/2007b/274/107.htm

SULBARÁN, J. La dimensión ética de la empresa. Documento de discusión realizado para Revista Económica, n ${ }^{\circ}$, Económicas y Sociales. Universidad de los Andes. (n.d.) 